\title{
COMPARATIVE STUDY OF CONTROLLER ADAPTIVE NEURAL FUZZY INFERENCE SYSTEM AND NEURAL WITH EXISTENCE OF ROTOR FAULT IN INDUCTION MACHINE
}

\author{
Kheira MENDAZ*, Houria BOUNOUA ${ }^{* *}$ \\ *University Centre Belhadj Bouchaib Ain Temouchent, IRECOM Laboratory, Electrical Engineering Department, \\ Ain Temouchent, 46000, Algeria, E-mail: kheiramendez@gmail.com \\ ** Djillali Liabes Unversity, School of Engineering Sciences, IRECOM Laboratory, Electrical Engineering Department, \\ Sidi Bel Abbes, 22000, Algeria
}

\begin{abstract}
The induction machine will play a role very important in the industry, but the existence of a certain defect returns their use limited as the defects rotor (broken bar). this article makes a comparative study of two Controller: adaptive Neural Fuzzy inference system (ANFIS) and neuronal with the existence of a rotor defect on the one hand and another hand of a defect of switch of the seven level inverter to see the influence of these two defects on the physical parameters of the machine. The application of ANFIS control with the existence of a broken bar in the motor allows us to see the effect of this fault on the motor parameters (speed, electromagnetic torque and current), to control itself is also used in existence of seven-level inverter fault (delay of blocking the switch) to give the results shown the swelling of this fault on the engine. After we passed to use the second control it is the neural control with the existence on one hand of the defect broken bar and on the other hand inverter fault, with this controller each fault influenced the parameters of Engine and can notice it from the simulation results.
\end{abstract}

The results, simulations are done by the use of Matlab/Simulink. Simulation results show clearly and robustness of tow controller ANFIS and neural.

Keywords: induction machine, rotoric faults, broken bar, seven Levels inverter, switch fault, ANFIS controller, neural controller

\section{INTRODUCTION}

Induction motor is widely used in the industrial applications and is a very important part to support industry in the manufacturing process due to its low cost, easy operation and simple maintenance. However, in recent years the induction motor drives have been able to be used in variable speed applications with the rapid development.

There are various faults occurring in the IM such as Broken Rotor Bar fault. Motor rotor faults are caused by a combination of various stresses that act on the rotor. The broken rotor bar is a common fault of the motor rotor. It can be caused by the following reasons: Thermal stresses due to thermal overload and unbalance, hot spots, or excessive losses, sparking, Magnetic stress caused by electromagnetic forces, unbalanced magnetic pull, electromagnetic noise, and vibration or residual stresses due to manufacturing problems.

Adaptive Network Fuzzy Inference System ANFIS is implemented as a Sugeno fuzzy inference system. ANFIS system allows the user to choose or modify the parameters of the membership functions based on the data. The parameters are adjusted automatically by the Neuro adaptive learning techniques like back propagation algorithm or hybrid method (which is a combination of back propagation and least squares methods). These techniques allow the fuzzy inference system to learn information about the data set. During the learning process, the parameters of the membership functions will be changed. The computations of these parameters can be controlled by using the optimization procedure which is defined by the sum of squard differences between actual and desired outputs. Sugeno systems are more compact and computationally efficient representation than a Mamdani system. [1][2][3]
This article speaks about tower controller (ANFIS and Neural controller) with existence of first hand the rotor broken bar and second hand the switch inverter fault. Result simulation using Matlab shows the effect of this controller.

\section{MATHEMATICAL MODELING OF THE INDUCTION MATOR}

The model of the induction motor is derived by using $\mathrm{d}$ and $\mathrm{q}$ variables in a synchronous rotating reference frame.

$$
\begin{aligned}
& \frac{d \Omega}{d t}=\frac{n_{p} L_{m}}{J L_{r}}\left(\Phi_{r d} I_{s q}-\Phi_{r q} I_{s d}\right)-\frac{1}{J} C_{r}-\frac{1}{J} f \Omega \\
& \frac{d I_{s d}}{d t}=-\lambda I_{s d}+\omega_{s} I_{s q}+\frac{K}{\tau_{r}} \Phi_{r d}+n_{p} \Omega K \Phi_{r q}+\frac{1}{\sigma L_{s}} V_{s d} \\
& \frac{d I_{s q}}{d t}=-\omega_{s} I_{s d}-\lambda I_{s q}-n_{p} \Omega K \Phi_{r d}-\frac{K}{\tau_{r}} \Phi_{r q}+\frac{1}{\sigma L_{S}} V_{s q} \\
& \frac{d \Phi_{r d}}{d t}=\frac{L_{m}}{\tau_{r}} I_{s d}-\frac{1}{\tau_{r}} \Phi_{r d}+\left(\omega_{s}-n_{p} \Omega\right) \Phi r q \\
& \frac{d \Phi_{r q}}{d t}=\frac{L_{m}}{\tau_{r}} I_{s q}-\left(\omega_{s}-n_{p} \Omega\right) \Phi_{r d}-\frac{1}{\tau_{r}} \Phi_{r q}
\end{aligned}
$$

With

$$
\begin{aligned}
& \tau_{r}=\frac{L_{r}}{R_{r}}, \sigma=1-\frac{L_{m}^{2}}{L_{s} L_{r}}: \text { Scattering coefficient Blondel } \\
& K=\frac{L_{m}}{\sigma L_{s} L_{r}}, \quad \lambda=\frac{1}{\tau_{s} \sigma}+\frac{1}{\tau_{r}}\left(\frac{1-\sigma}{\sigma}\right)
\end{aligned}
$$




\section{THE ROTORIC FAULT MODEL OF THE INDUCTION MACHINE}

It is necessary to develop a model of rotoric fault that explains the disequilibrium who transit a minimum of parameters, these parameters must be the image of the fault presented in the machine [3] [2].

The Fig. 1 illustrated the conventional modeling of the rotor elementary dipoles with one broken bar.

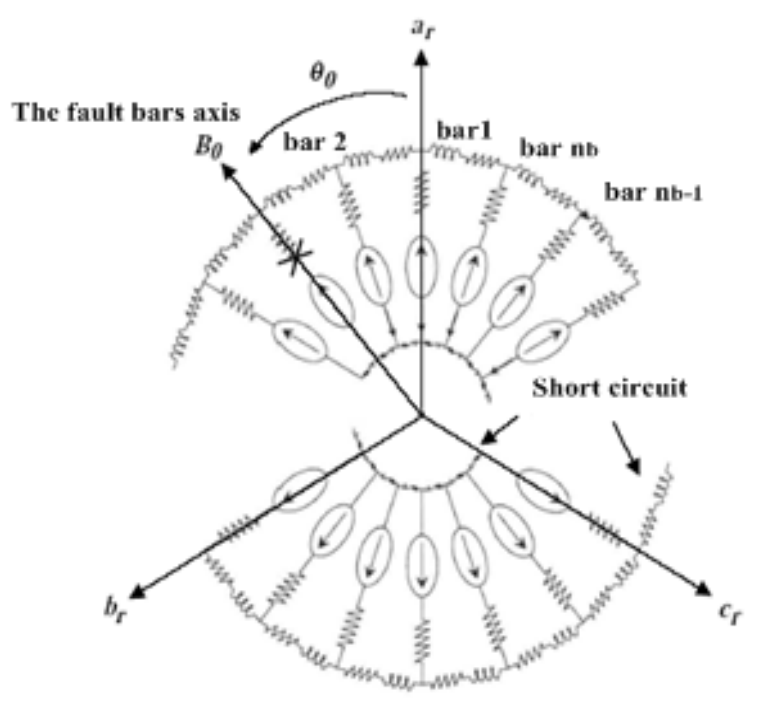

Fig. 1 Modelisation of elementary dipoles for rotoric fault

\section{Modelisation of Broken Bars}

The voltage and flux equations when there is a fault in the coil $B_{0}$ can write as:

$0=n_{0} R_{r} \mathrm{I}_{0}+\frac{d \Phi_{0}}{d t}$

$\Phi_{0}=\frac{2}{3} n_{0}^{2} L_{m} I_{0}+\sqrt{\frac{2}{3}} n_{0} L_{m}\left[\cos \left(\theta_{0}\right) \sin \left(\theta_{0}\right)\right]\left(I_{d q s}+I_{d q r}\right)$

The current in the coil $I_{0}$ represented the fault that was the original stationary magnetic field $H_{0}$ as well as the rotor that oriented on the axis $\theta_{0}$. This magnetic field is the origin of the flux $\Phi_{0}$. We are projecting $I_{0}$ and $\Phi_{0}$ on the axis $d$ and $q$ of Park, and we can associate for there the stationary vectors:

$I_{d q 0}=\left[\begin{array}{cc}\cos \left(\theta_{0}\right) \\ \sin \left(\theta_{0}\right)\end{array}\right] I_{0}, \Phi_{d q 0}=\left[\begin{array}{cc}\cos & \left(\theta_{0}\right) \\ \sin & \left(\theta_{0}\right)\end{array}\right] \Phi_{0}$

The relation (8) and (9) becomes a relation between stationary vector as well as the rotor. The sum machine equations of the stator, rotor and coil $B_{0}$ given by this new equation [4][1][2]:

$$
\begin{aligned}
& {\left[U_{d q s}\right]=R_{s} I_{d q s}+\frac{d \Phi_{d q s}}{d t}+w p\left(\frac{\pi}{2}\right) \Phi_{d q s}} \\
& \Phi_{d q s}=L_{f} I_{d q s}+L_{m}\left(I_{d q s}+I_{d q r}+\sqrt{\frac{2}{3} n_{0}} I_{d q 0}\right)
\end{aligned}
$$

$0=\left[R_{r}\right] \mathrm{I}_{d q r}+\frac{d \Phi_{d q r}}{d t}$

$\Phi_{d q r}=L_{m}\left(I_{d q s}+I_{d q r}\right)+\sqrt{\frac{2}{3}} n_{0} L_{m} I_{d q 0}$

$0=n_{0} R_{r} \mathrm{I}_{d q 0}+\frac{d \Phi_{d q 0}}{d t}$

$\Phi_{d q 0}=\sqrt{\frac{2}{3}} n_{0} L_{m} \Phi\left(\theta_{0}\right)\left(I_{d q s}+I_{d q r}+\sqrt{\frac{2}{3}} n_{0} I_{d q 0}\right)$

With

$\Phi\left(\theta_{0}\right)=\left[\begin{array}{cc}\cos \left(\theta_{0}\right)^{2} & \cos \left(\theta_{0}\right) \sin \left(\theta_{0}\right) \\ \cos \left(\theta_{0}\right) \sin \left(\theta_{0}\right) & \sin \left(\theta_{0}\right)^{2}\end{array}\right]$

The detection, fault of broken bars of the induction machine can be obtained by the following equation:

$$
\begin{aligned}
& x^{*}=f(x)+g \cdot u \\
& y=h(x)+H(x) \cdot u
\end{aligned}
$$

With

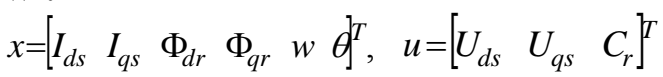

$y=\left[\begin{array}{lll}I_{d s} & I_{q s} & w\end{array}\right]^{T}$

$h(x)=\left[\begin{array}{c}I_{d s} \\ I_{q s} \\ w\end{array}\right]$

$f(x)=\left[\begin{array}{c}-\left(\left(R_{s} I+R_{e q}\right) L_{f}^{-1}+w p\left(\frac{\pi}{2}\right)\right) I_{d q s}+\left(R_{e q} L_{m}^{-1}-w p\left(\frac{\pi}{2}\right)\right) L_{f}^{-1} \Phi_{d q r} \\ R_{e q} I_{d q s}-R_{e q} L_{m}^{-1} \Phi_{d q r} \\ \frac{p^{2}}{2}\left(I_{q s} \Phi_{d r}-I_{d s} \Phi_{q r}\right)-\frac{f_{r}}{J} w\end{array}\right]$

$g=\left[\begin{array}{cccc}\frac{1}{L_{f}} & 0 & 0 \\ 0 & \frac{1}{L_{f}} & 0 & \\ 0 & 0 & 0 & \\ 0 & 0 & 0 & \\ 0 & 0 & - & \frac{p}{J} \\ 0 & 0 & 0 & \end{array}\right] \begin{aligned} & R_{e q}=R_{r} \\ & \text { where } \\ & \alpha=\frac{2}{3} n_{0}\end{aligned}$

\section{STRUCTURE OF THE SEVEN LEVELS INVERTER ASSOCIATED WITH INDUCTION MACHINE}

The three-phase inverter, on seven levels with structure studies in this paragraph consists of three symmetrical arms and six sources of equal continuous voltage. Each arm comprises twelve switches of which eights are in series and four in parallel, like two diodes for the zero setting of the arm of the inverter. Each switch is composed of a GTO and of a diode assembled at the head digs as it is shown in the Fig. 2 for this inverter; we chose 
the complementary order defined as follows. [9] [10] [11] [12]

$$
\begin{aligned}
& B_{K 5}=\bar{B}_{K 3}, B_{K 6}=\bar{B}_{K 4}, B_{K 7}=\bar{B}_{K 1} \\
& B_{K 8}=\bar{B}_{K 2}
\end{aligned}
$$

With $\mathrm{B}_{\mathrm{KS}}$ : basic control of the switch $\mathrm{KS}$

$\mathrm{K}$ of the arm $\mathrm{k}(\mathrm{k}=\mathrm{R}, \mathrm{S}, \mathrm{T})$.

$\mathrm{Ki}=1$ : Show the closed of high switch and opened of law switch.

$\mathrm{Ki}=0$ : Show the opened of high switch and closed of law switch.

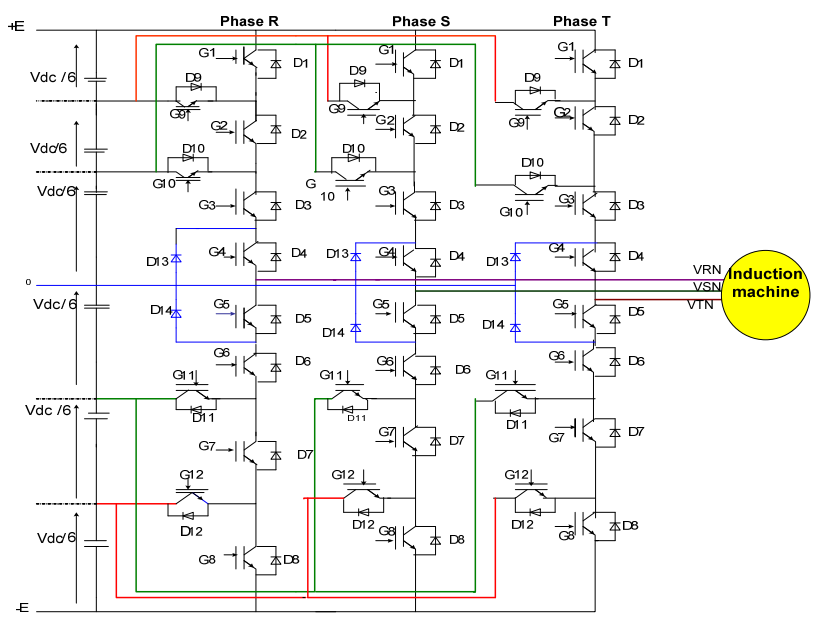

Fig. 2 The seven levels inverter structural

\section{DIAGNOSTICS FAULTS OF SEVEN LEVELS INVERTER}

In the inverter seven levels, the voltage of phases represented twenty and one level under symmetrical functional, but their levels of voltage seem to be different with each fault from commutation. The voltage of phase of the positive period has only eight levels because the current of phase cross the $\mathrm{K}_{19}$ switch instead of $\mathrm{K}_{11}$ in the state of $\mathrm{P}$ (positive). In the event of fault of commutation of $\mathrm{K}_{110}$, the voltage of phase of the positive period has only six levels because the current of phase crosses the $\mathrm{K}_{110}$ switch in the state of $\mathrm{P}$ (positive). In the event of fault of commutation of $\mathrm{K}_{13}$, the voltage of phase for the positive period has only four levels because the current of phase cross the $\mathrm{K}_{14}$ switch in the $\mathrm{P}$ (positive). Consequently, when each fault of commutation occurs, the fictitious voltage was differently appeared between them. [10][11][12]

The fault of K19 induces disequilibrium in the three phases, which translates by the discharge of the lower condensers of the arm $\mathrm{R}$ for the five level inverter.

K12: the switch of first arm (phase R) composed for [G2, D2].

K11: the switch of first arm (phase R) composed for [G1, D1].

K13: the switch of first arm (phase R) composed for [G3, D3].

K17: the switch of first arm (phase R) composed for [G7, D7].

K19: the switch of first arm (phase R) composed for [G9, D9].

K110: the switch of first arm (phase R) composed for [G10, D10].

\section{CONSTRUCTION OF NEURAL NETWORK}

Supervise techniques for neural networks are based on the existence of a database of training data, from which one seeks to find a relationship between the input variables and output variables. From these input variables, the neural network provides a response characterized by two types of output variables.

Actual output variables which can represent an estimate of the supervise parameter or output categorical variables that represent the state of functionality equipment.

The type of neural network application in the supervise domains is related to the nature of the output data.

Determining the neural model for the identification is an essential phase, which may be more or heavy months of executing the industrial diagnosis.

The algorithm allows us to select the robust neural model, for identification will be aspire in the following steps: [13][14]

a) The knowledge about the system to be identified.

b) Choisen of the inputs and outputs of the neural model.

c) Determination of the internal behavior of the number of neurons in each hidden layer).

d) Choisen of activation functions.

e) Choisen of accuracy and the number of iteration.

The structural multi layer perceptron used in the neural network of the asynchronous machine is given in Fig. 3.

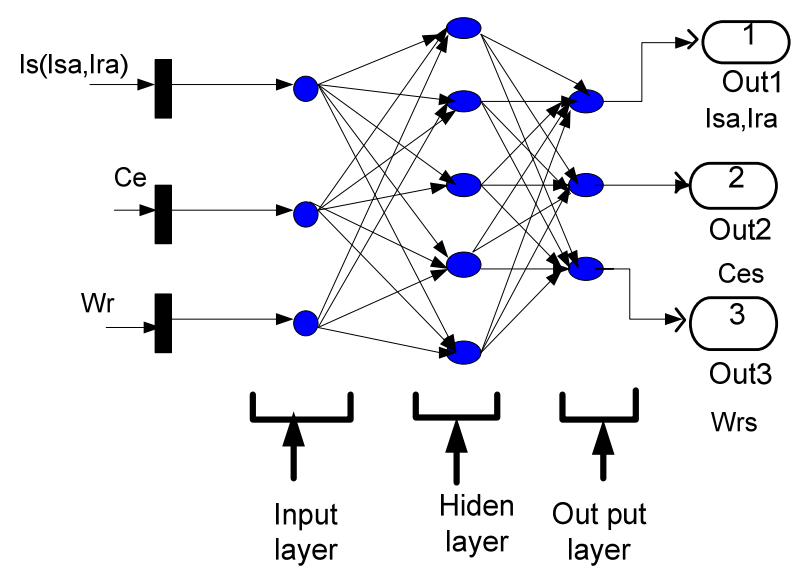

Fig. 3 Multilayer perceptron, structural $(3,5,3)$

$\mathrm{C}_{\mathrm{e}}$ : Input electromagnetique torque of neural network. $\mathrm{W}_{\mathrm{r}}$ : Input measured speed of neural network. $\mathrm{I}_{\mathrm{s}}\left(\mathrm{I}_{\mathrm{sa}}, \mathrm{I}_{\mathrm{ra}}\right)$ : Input statoric, rotoric current of neural network.

The mathematical model of neural given by the following equation:

$y=\sum_{i=l}^{n} w_{i} x_{i}+b$

$y$ : Output neural, $\left(x_{1}, x_{2}, \ldots, x_{n}\right)$ are the inputs neural, $\left(w_{1}, w_{2}, \ldots, w_{n}\right)$ the correspondence heaviness and $b$ is bias of neuron.

After the upload of the output and input, we created a neural network of three layers (two input layer, one output 


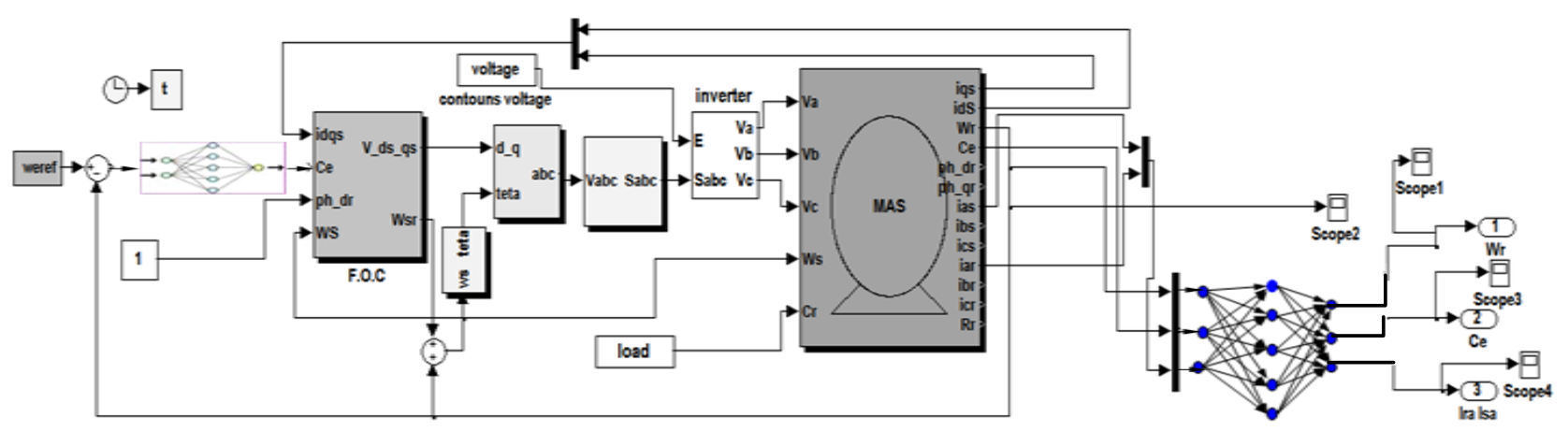

Fig. 4 Command of induction machine with application of regulator neural network

layer and five hidden layers), by the utilization of Matlab"newff" function, and the chosening of learning function"trainlm". However if the neural network is constructed and the learning afflicted the satisfactory performances, we utilized the Matlab function "train" and simulated the results (utilization of Matlab function "sim").

In the first regulator neural network, the error speed $\left(W_{\text {rref }}-W_{r}\right)$ is the input of neural network, and the electromagnetic torque $\left(\mathrm{C}_{\mathrm{e}}\right)$ is the output of neural network, this controller use for regulation of speed.

In the second controller neural network, in our model of induction machine, the speed $\mathrm{Wr}$, electromagnetic torque $\mathrm{C}_{\mathrm{e}}$ and the statoric, rotoric current $\mathrm{I}_{\mathrm{s}}$ are the inputs of neural network, and the $\left(\mathrm{C}_{\mathrm{es}}, \mathrm{W}_{\mathrm{rs}}, \mathrm{I}_{\mathrm{sa}}\right.$ and $\left.\mathrm{I}_{\mathrm{ra}}\right)$ are the outputs of neural network which designated the value $\left(\begin{array}{ll}0 & 0\end{array}\right.$ $10)$, so the corresponding fault: broken bars.

0 : there is not a fault. 1 : induces of fault.

The Fig. 5 shows the position of neural.
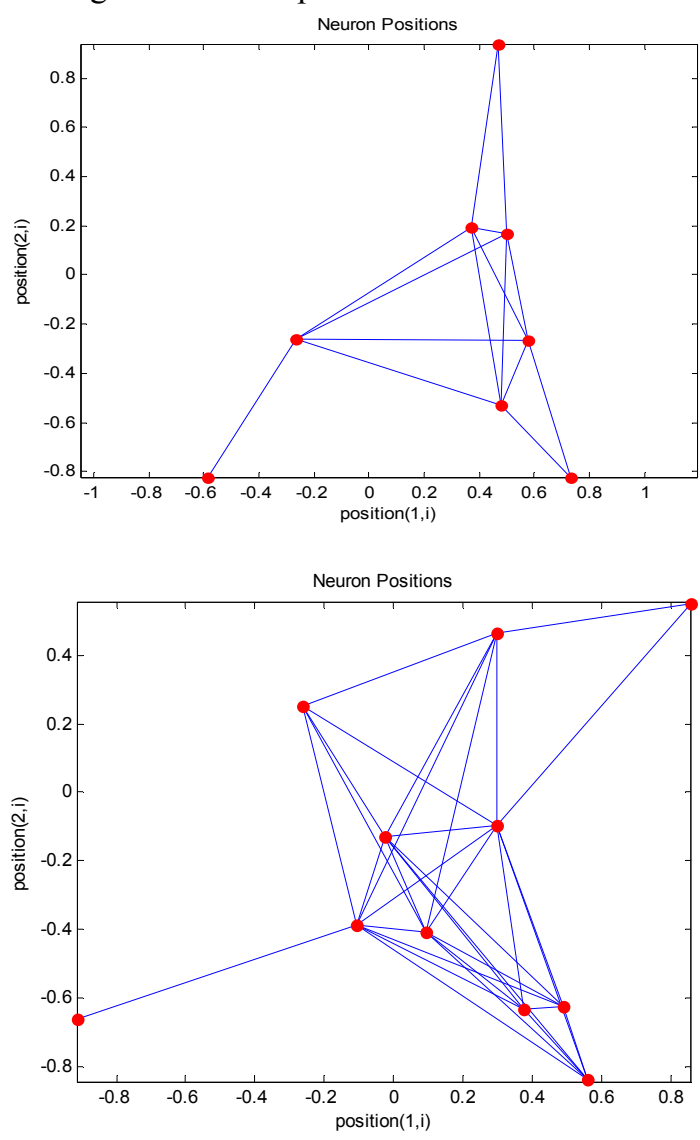

Fig. 5 Neuron position for the first and second controller Neural

\section{STRUCTURE OF ANFIS SYSTEM}

The Neuro-fuzzy system combines the learning capabilities of neural networks with the linguistic rule interpretation of a fuzzy inference system. The proposed Neuro-fuzzy controller incorporates a fuzzy logic algorithm with a five layer artificial neural network (ANN) structure as shown in Fig. 6. ANFIS architecture that has two inputs $e$ and $\Delta e$ and one output $\mathrm{C}_{\mathrm{e}}$. [7][8][5] [6]

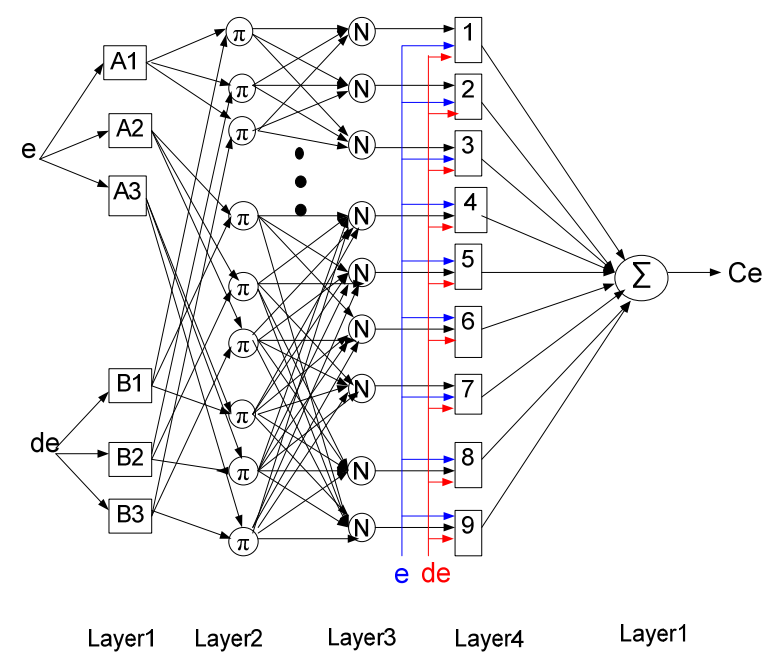

Fig. 6 Structure of ANFIS controller for induction motor

Layer 1: This layer is Fuzzification layer. Degrees of membership functions are calculated in this layer for each input variable. The input variables of ANFIS are chosen as the error $(e)$ and the change of error $(\Delta e)$ that given by Equation (13), (14). Every node $i$ in this layer is an adaptive node with node function:

$$
\begin{aligned}
& x=e(t) \\
& y=\Delta e(t) \\
& e(t)=w^{*}-w_{r} \\
& \Delta e(t)=e(t)-e(t-1)
\end{aligned}
$$

Layer 2: This layers (membership layer) check for the weights of each MF. It receives the input values from the $1^{\text {st }}$ layer and act as MF to represent the fuzzy sets of the respective input variables. Further, it computes the membership values which specify the degree to which the 
input value belongs to the fuzzy set, which acts as the inputs to the next layer.

$$
O_{i}^{2}=W_{i}=\mu_{A i}\left(x_{1}\right) \cdot \mu_{B i}\left(x_{2}\right), \quad i=1,2,3 . .
$$

Layer 3: This layer is called as the rule layer. Each node (each neuron) in this layer performs the precondition matching of the fuzzy rules, i.e., they compute the activation level of each rule, the number of layers being equal to the number of fuzzy rules. Each node of these layers calculates the weights which are normalized.

$O_{i}^{3}=v_{i}=\frac{W_{i}}{\sum_{k} W_{k}}$

Or $W_{i}$ and $v_{i}(i=1 \ldots .6)$ are the order of output signals $i$ of the second and third layer respectively.

Layer 4: This layer is called as the Defuzzification layer and provides the output values $y$ resulting from the inference of rules. Connections between the layers and are weighted by the fuzzy singletons that represent another set of parameters for the Neuro fuzzy network.

$$
O_{i}^{4}=v_{i} f_{i}=v_{i}\left(p_{i} x+q_{i} y+r_{i}\right)
$$

Where ANFIS is a normalized firing strength from layer 3 , and $\left\{p_{i}, q_{i}, r_{i}\right\}$ is the parameter set of this node.

Layer 5: This layer is called as the output layer which sums up all the inputs coming from the layer 4 and transforms the fuzzy classification results in a crisp (binary).
$O_{i}^{4}=\sum v_{i} f_{i}$

The Fig. 7 illustrated the application of the Adaptive Network based Fuzzy Inference System controller for the first controller that use for regulation of speed and the second that use for show the effect of broken bar and inverter fault on the physical parameter of the motor.

\section{RESULTS AND DISCUSSION}

The simulation was elaborated on Matlab/Simulink for the induction machine associated with seven levels inverter.

For showing the effect of broken bars on induction machine with utilization of Adaptive Network Fuzzy Inference System controller (show the effect of the broken bars on simulated vectors: speed $\left(\mathrm{W}_{\mathrm{r}}\right)$, electromagnetic torque $\left(\mathrm{C}_{\mathrm{e}}\right)$ and the statoric and rotoric current $\left.\mathrm{I}_{\mathrm{sa}}, \mathrm{I}_{\mathrm{ra}}\right)$, and the effect of switching fault for the inverter on the simulated vector for the induction machine.

\section{Bars fault}

The type of fault that we study is the broken bars of the cage asynchronous machine.

Utilization of Adaptive Network Fuzzy Inference System controller for the detection of broken bars gives the following results.

Fig. 9 and 10 represent the characteristics of the sound machine with application of load torque of $10 \mathrm{Nm}$ at $\mathrm{t}=$ $(1.5 \mathrm{~s}, 2 \mathrm{~s})$ and the existence of fault rotoric (one broken bar at $\mathrm{t}=(1 \mathrm{~s}, 1.5 \mathrm{~s})$ and two broken bars at $\mathrm{t}=(2 \mathrm{~s}, 2.5 \mathrm{~s}))$.

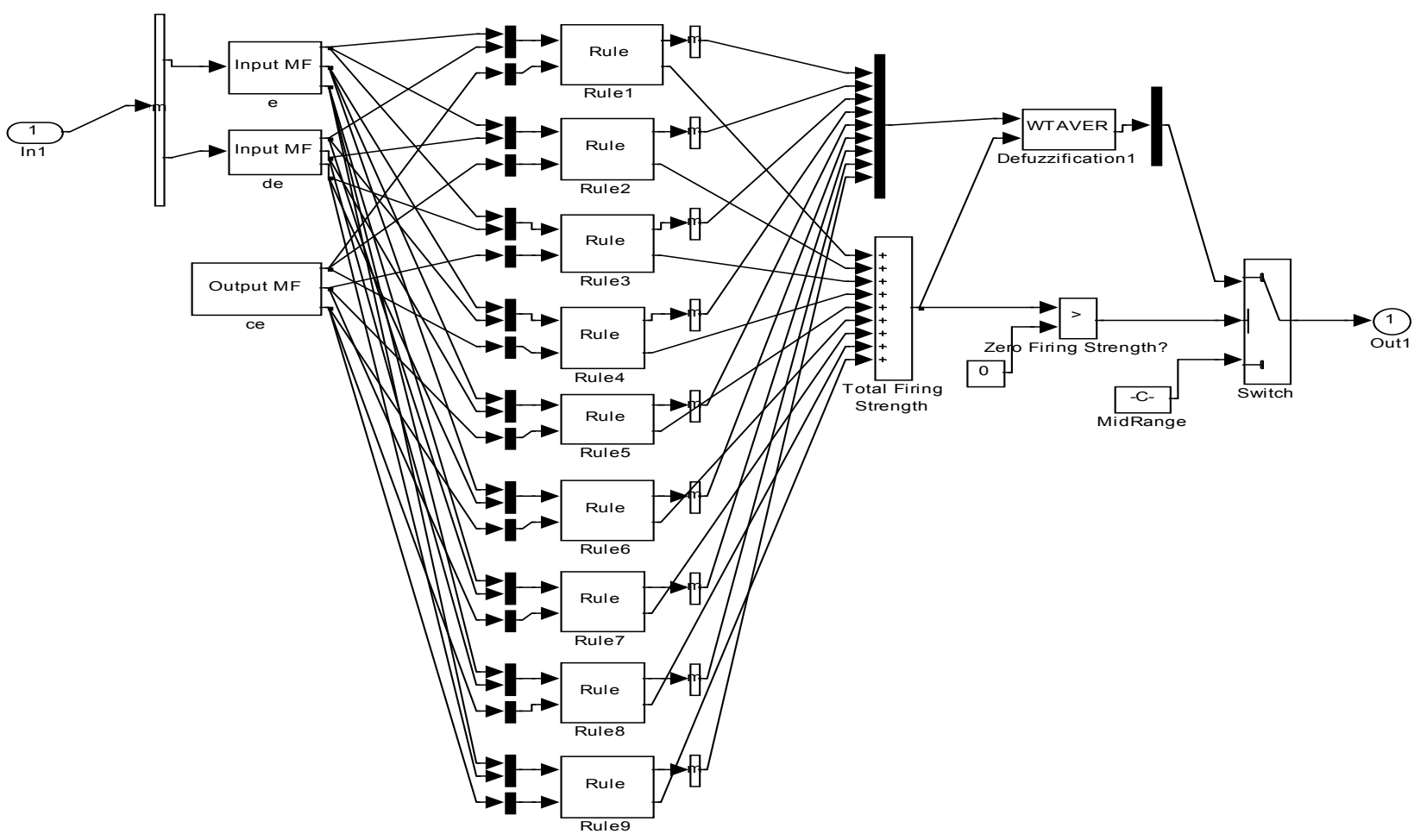



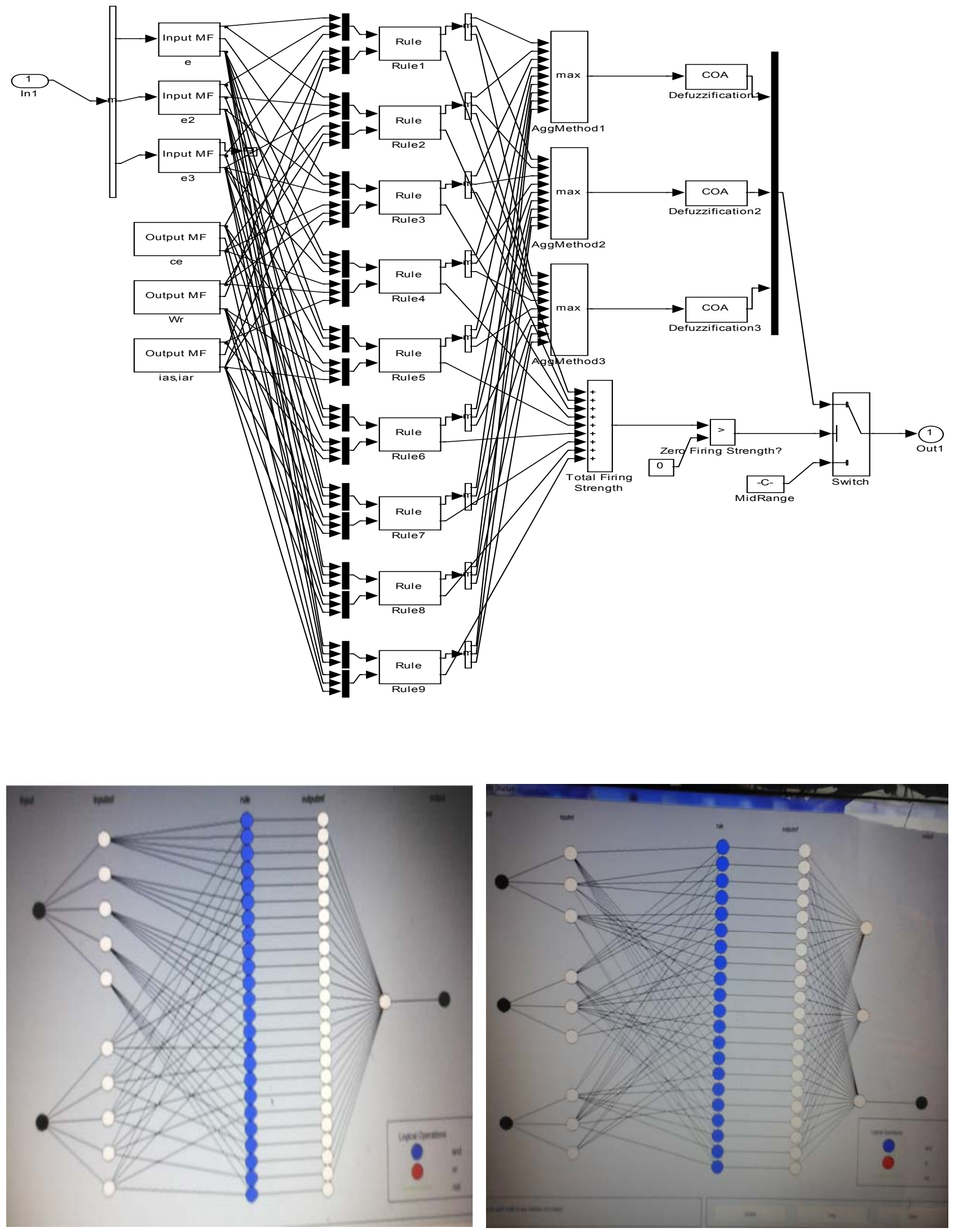

Fig. 7 The ANFIS structure in Matlab-Simulink for the first and second controller 


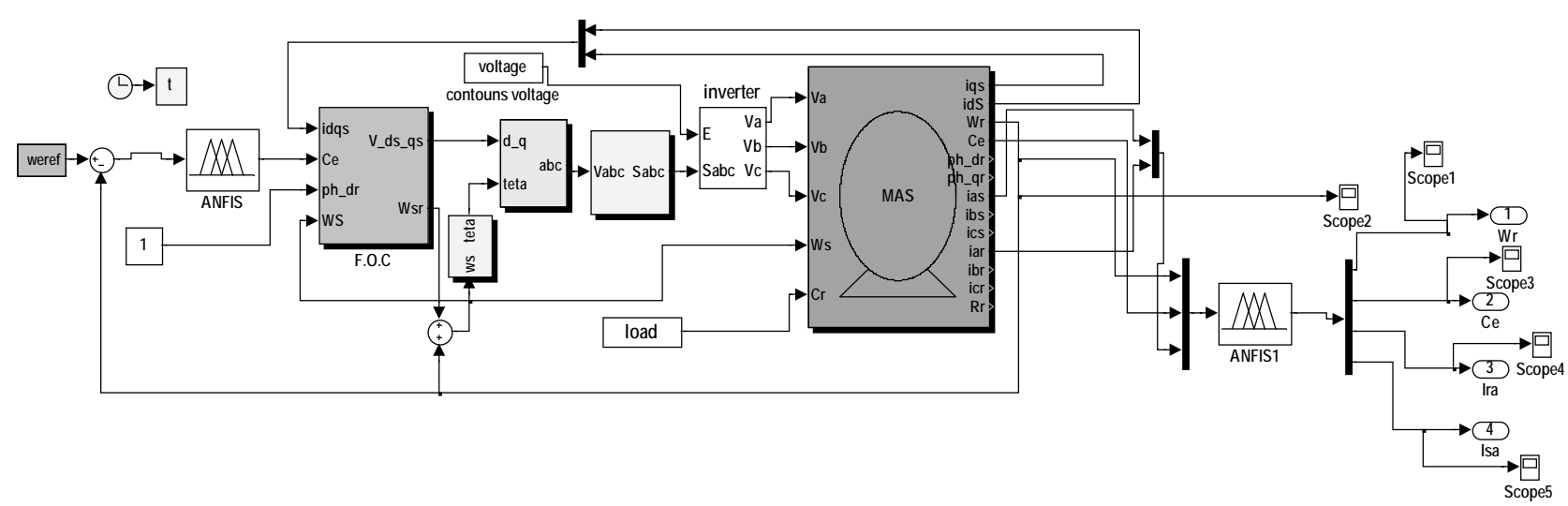

Fig. 8 Command of induction machine with application of Adaptive Network Fuzzy Inference System controller

The analysis of the electromagnetic torque (Fig. 9) shows a significant change in its appearance when rotor faults occur. The presence of an oscillation, when there is a rotoric fault of the machine, is due to the consideration of space harmonics in the model.

We observe a slight modulation disturbs the evolution of torque when the first bar is broken at $t=(1 \mathrm{~s}, 1.5 \mathrm{~s})$. We also note that this modulation becomes more important with the advent of the second fault at $t=(2 \mathrm{~s}, 2.5 \mathrm{~s})$. In theory, this amplitude modulation is identical to the speed, frequency $2 \mathrm{gf}$ but as we can see, it is relatively difficult to discern with a simple visual analysis. We note that the first broken bar indicates a very small increase in the current flowing through the rotor (Fig. 10).

The application of neural controller for detection of rotor broken bars illustrated in the Fig. 14 and Fig. 15.

In the application of a neuronal controller during the rotor defect (broken bars) in the remark of the disturbance on the electromagnetic torque signal and the speed lasting of one bar, this disturbance increasement at the time of tow broken bars (Fig. 14). Concerning the stator and rotor current there exists on their signals the undulations and oscillations during the two defects (Fig. 15).

\section{Inverter fault}

The use of controlled adaptive Neural fuzzy inference system during the existence of a defect of the $\mathrm{K}_{19}$ switch of the inverter seven levels show the effect of this fault on the physical parameters of the induction machine that we can see the cancellation of the electromagnetic torque signal during the defect (Fig. 12) and even in the remark it with the answers of the stator and rotor current (Fig. 13). Contrary for the speed which is increased when the defects of the $\mathrm{K}_{19}$ switch to reach (Fig. 13).

From the seven levels inverter with application of neural controller we show that the voltage and the currents $\mathrm{I}_{\mathrm{sa}}, \mathrm{I}_{\mathrm{ra}}$ resulting from the faults of the switches $\mathrm{K}_{19}$ illustrated by the Fig. 16 and the Fig. 18, that notice how the faults of this switcher $\mathrm{K}_{19}$ induces a disequilibrium on these currents and voltage.

The Fig. 17 represented the lead of induction machine before and during the fault, which are translated by an increasement of speed and oscillations of the torque. After this fault we have a decreasement of speed.

If they have a production of the fault in the seven level inverter, the current deporting in the medium point caused a ground effect on the charge/discharges condensers variation. The fault in high switchers, produce an increasement in lower discharges condensers, and the voltage level appears to be different for each switching fault, this disadvantage of five levels inverter has an influence on the induction machine.
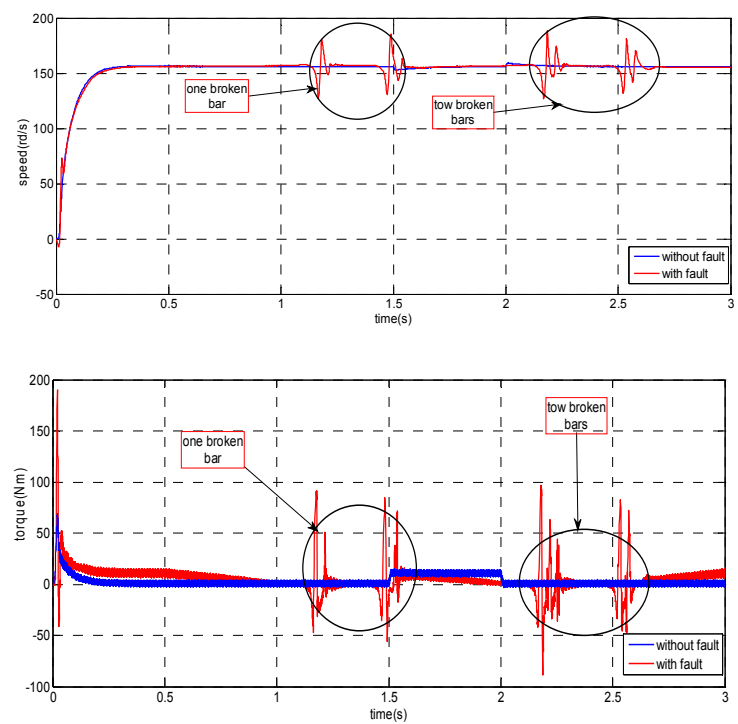

Fig. 9 Speed and electromagnetic torque result of induction machine without fault and with fault with one broken bar at $\mathrm{t}=$ $(1 \mathrm{~s}, 1.5 \mathrm{~s})$ and tow broken bars at $\mathrm{t}=(2 \mathrm{~s}, 2.5 \mathrm{~s})$ with application of load torque $\mathrm{Cr}$ at $\mathrm{t}=(1.5 \mathrm{~s}, 2 \mathrm{~s})$ of adaptive Neural Fuzzy inference system controller
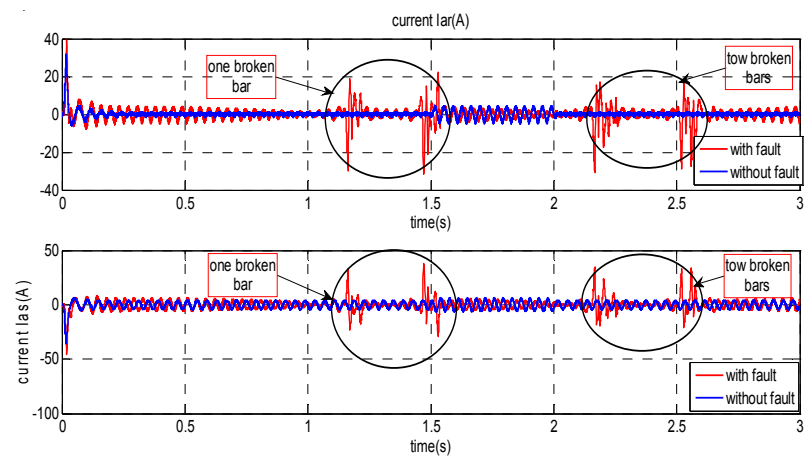

Fig. 10 The current $I_{s a}, I_{r a}$ result of induction machine without fault and with one broken bar at $\mathrm{t}=(1 \mathrm{~s}, 1.5 \mathrm{~s})$ and tow broken bars at $\mathrm{t}=(2 \mathrm{~s}, 2.5 \mathrm{~s})$ with application of load torque $\mathrm{Cr}$ at $\mathrm{t}=$ $(1.5 \mathrm{~s}, 2 \mathrm{~s})$ of adaptive Neural Fuzzy inference system controller. 


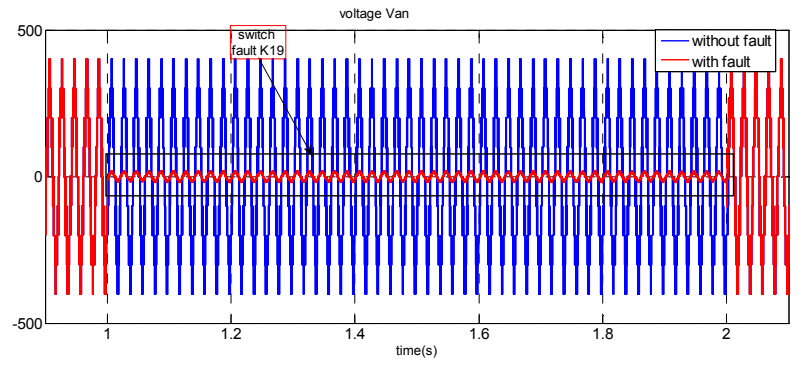

Fig. 11 The voltage results $V_{\text {an }}$ of five levels inverter with fault of switch $\mathrm{K}_{19}$ at $\mathrm{t}=(1 \mathrm{~s}, 2 \mathrm{~s})$ of adaptive Neural Fuzzy inference system controller
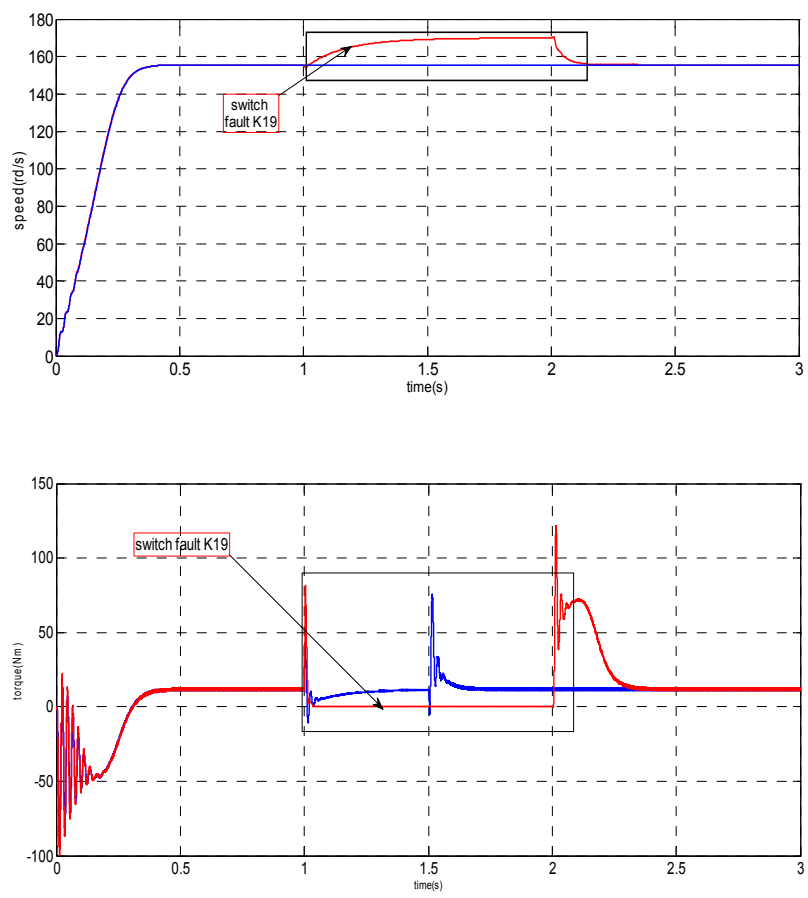

Fig. 12 Speed and electromagnetic torque results of induction machine with switch fault of seven levels inverter $\mathrm{K}_{19}$ at $\mathrm{t}(1 \mathrm{~s}$, $2 \mathrm{~s})$ and application of load torque $\mathrm{Cr}$ at $\mathrm{t}=(1 \mathrm{~s}, 1.5 \mathrm{~s})$ of adaptive Neural Fuzzy inference system controller
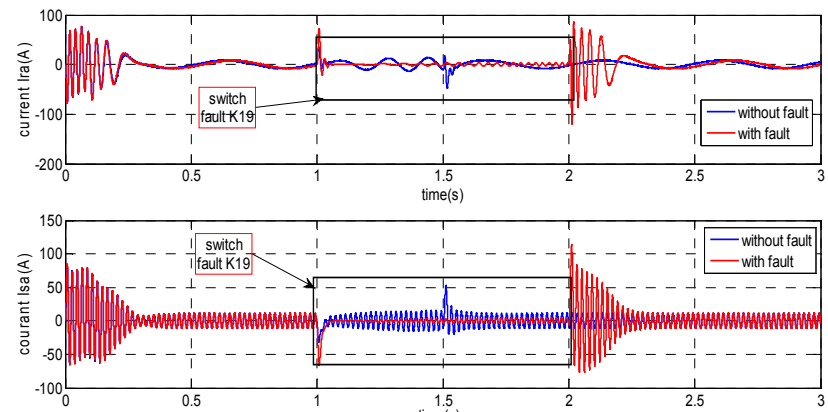

Fig. 13 The current $I_{\mathrm{sa}}, I_{\mathrm{ra}}$ result of induction machine with fault in switch of seven levels inverter $\mathrm{K}_{19}$ at $\mathrm{t}(1,2 \mathrm{~s})$ and application of load torque $\mathrm{Cr}$ at $\mathrm{t}=(1 \mathrm{~s}, 1.5 \mathrm{~s})$ of adaptive Neural Fuzzy inference system controller
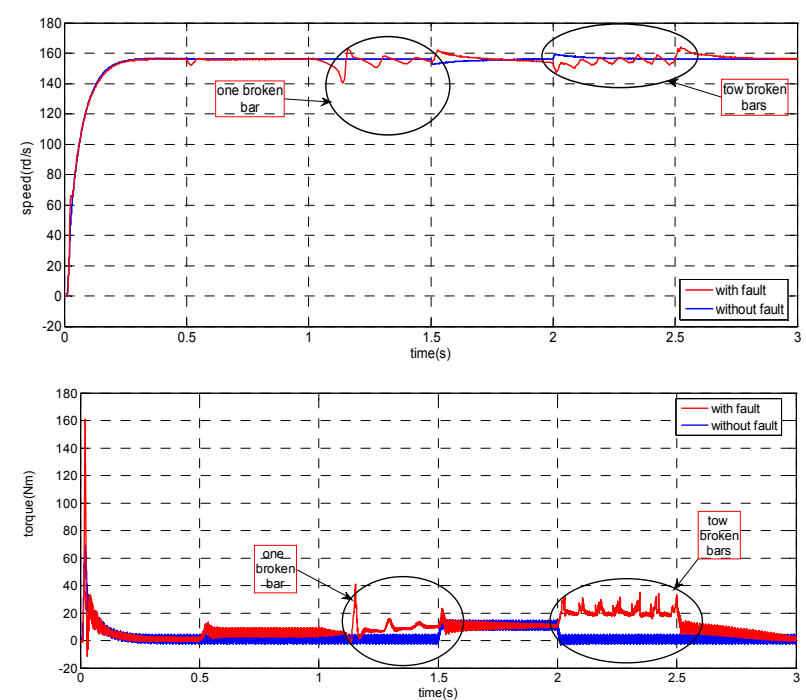

Fig. 14 Speed and electromagnetic torque result of induction machine without fault and with fault with one broken bar at $\mathrm{t}=$ $(1 \mathrm{~s}, 1.5 \mathrm{~s})$ and tow broken bars at $\mathrm{t}=(2 \mathrm{~s}, 2.5 \mathrm{~s})$ with applicationof load torque $\mathrm{Cr}$ at $\mathrm{t}=(1.5 \mathrm{~s}, 2 \mathrm{~s})$ of Neural controller
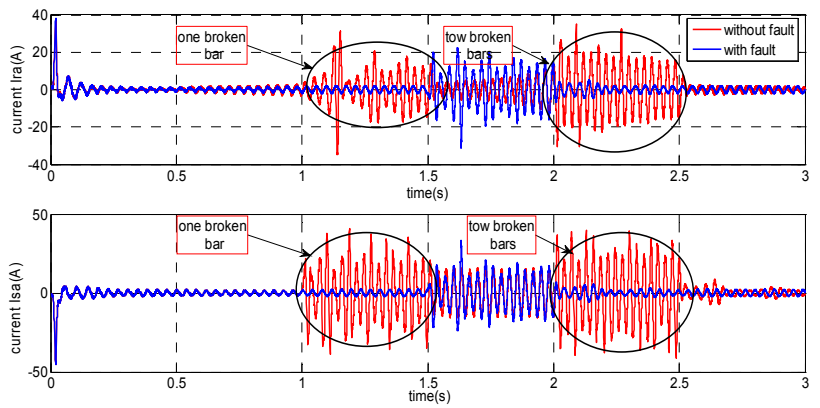

Fig. 15 The current $I_{s a}, I_{r a}$ result of induction machine without fault and with one broken bar at $\mathrm{t}=(1 \mathrm{~s}, 1.5 \mathrm{~s})$ and tow broken bars at $\mathrm{t}=(2 \mathrm{~s}, 2.5 \mathrm{~s})$ with application of load torque $\mathrm{Cr}$ at $\mathrm{t}=$ $(1.5 \mathrm{~s}, 2 \mathrm{~s})$ of Neural controller
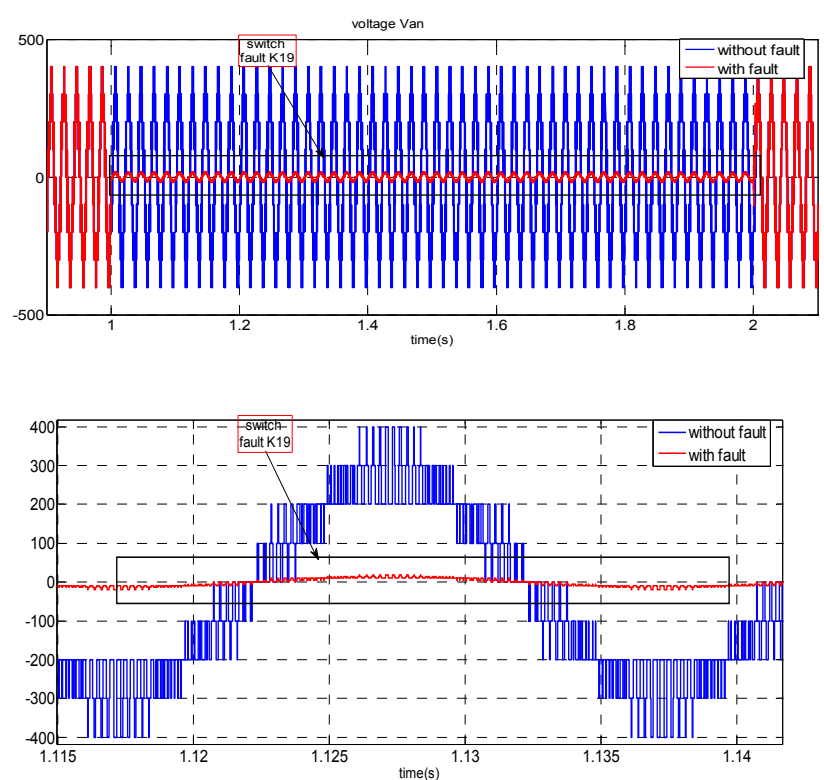

Fig. 16 The voltage results $V_{\text {an }}$ of five levels inverter with fault of switch $\mathrm{K}_{19}$ at $\mathrm{t}=(1 \mathrm{~s}, 2 \mathrm{~s})$ and their zom of Neural controller 

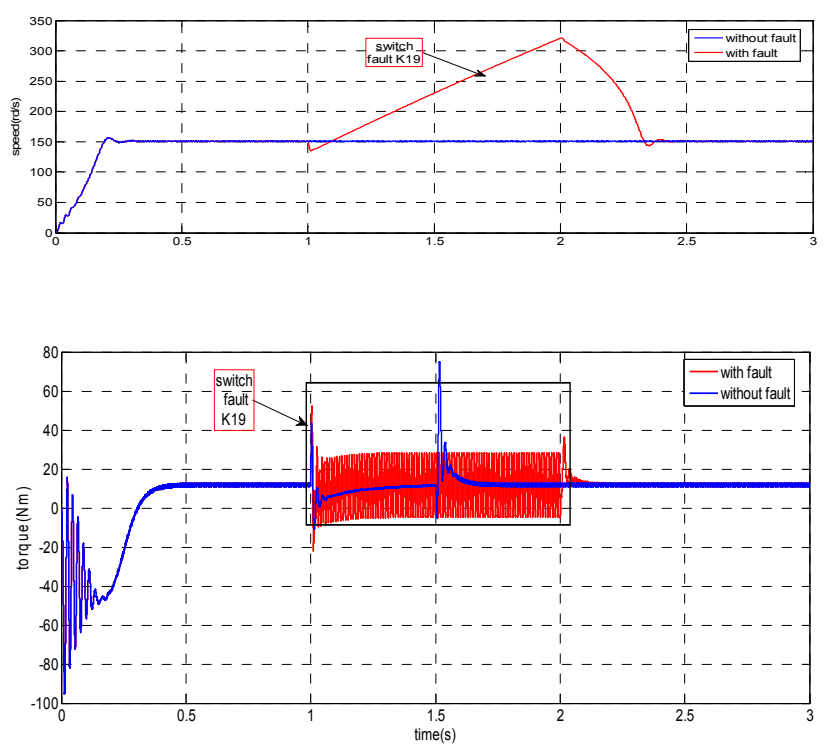

Fig. 17 Speed and electromagnetic torque results of induction machine with switch fault of seven levels inverter $\mathrm{K}_{19}$ at $\mathrm{t}(1 \mathrm{~s}$, $2 \mathrm{~s})$ and application of load torque $\mathrm{Cr}$ at $\mathrm{t}=(1 \mathrm{~s}, 1.5 \mathrm{~s})$ of Neural controller
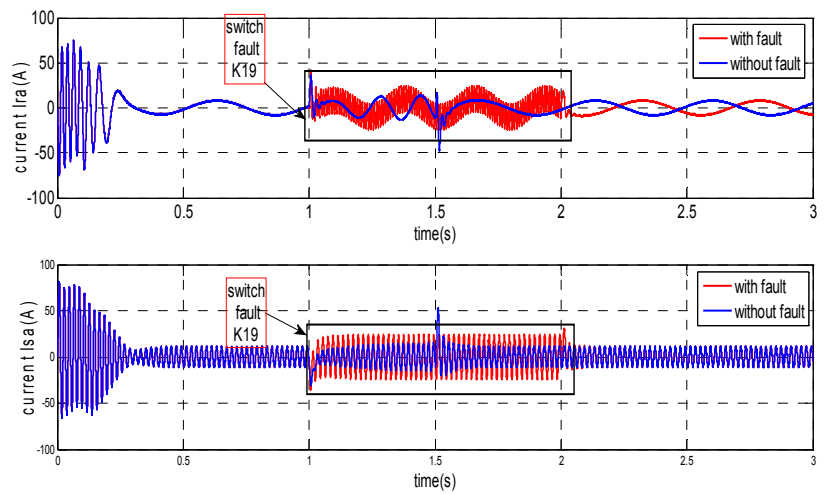

Fig. 18 The current $I_{\mathrm{sa}}, I_{\mathrm{ra}}$ result of induction machine with fault in switch of five levels inverter $\mathrm{K}_{19}$ at $\mathrm{t}(1,2 \mathrm{~s})$ and application of load torque $\mathrm{Cr}$ at $\mathrm{t}=(1 \mathrm{~s}, 1.5 \mathrm{~s})$ of Neural controller

\section{CONCLUSIONS}

Each of these two controller that we presented (ANFIS and neuronal To control) for a rotor fault existence or for a defect of switch of the seven levels inverter gives results different, but perfermant, each regulator enables us to have the influence of the existence of a defect on the physical parameters of the induction machine (speed, electromagnetic couple and the two stator current and rotor) which is in the undulation and the oscillation which disturbed various signals, its enables us to conclude deterioration and damage system for the presence of these defects.

\section{REFERENCES}

[1] ASHOK, K. - SHANKARAPPA, F. K. - SANKER, R: Modelling \& Simulation of an ANFIS controller for an AC drive, World Journal of Modelling and Simulation, Vol. 8, No. 1, 2012, pp. 36-49.
[2] BENMILOUD, T.: Simulation of the adaptive Neuro-fuzzy inference system (ANFIS) inverse controller using Matlab S-function, Academic Journals, Vol. 8, No. 21, 2013, pp. 875-884.

[3] KHUSHBOO, A. - VIVEK. V. - ANWAR, M. M.: ANFIS Based Analysis of Three-Phase Self-Excited Induction Generator, International Journal of Emerging Technology and Advanced Engineering, Vol. 4, No. 1, 2014, pp. 114-120.

[4] SUMIYA ANJUM, I. - DINESH PRABU, V. K. KUMAR, C.: An Adaptive Neuro Fuzzy Based Speed Control of an Induction Motor Drive Using Unscented Kalman Filter, International Journal of Emerging Technology and Advanced Engineering, Vol. 4, No. 3, 2014, pp. 114-120.

[5] RAJAJI, L. - KUMAR, C. - VASUDEVAN, M.: Fuzzy and ANFIS Based Soft Starter FED Induction Motor Drive for High Performance Applications, ARPN Journal of Engineering and Applied Sciences, Vol. 3, No. 4, 2008, pp. 12-24.

[6] CHANDRALEKHA, R. - JAYANTHI, D.: Diagnosis of Faults in Three Phase Induction Motor using Neuro Fuzzy Logic, International Journal of Applied Engineering Research, Vol. 11, No. 8, 2016, pp. 5735-5740.

[7] SRIDHAR, S. - UMA RAO, K. - HARISH, K. S. RAKSHA UMESH: Simultaneous Detection of Broken Rotor Bar Fault and PQ disturbances in the Supply to Induction Motor Using Neuro-Fuzzy, International Journal of Innovative Research in Science, Engineering and Technology, Vol. 5, No. 9, 2016, pp 596-607.

[8] PRIYANKA, D. - DHARMENDRA, K. S. DURGA, S.: Modeling And Simulation Of Rotor Side Fault Diagnosis Of Induction Motor By Using Fuzzy Based Controlled Identifier, International Journal of Engineering Research and General Science, Vol. 3, Issue 3, 2015, pp. 1521-1530.

[9] SEGUIER, G. - LABRIQUE, F.: les convertisseurs de l'électronique de puissance, Vol. 4, technique et documentation-Lavoisier, 1989.

[10] OUHID, B.: la contribution de l'analyse des onduleurs multi niveaux, mémoire de magister, 2005.

[11] MENDAZ, K. - BOUNOUA, H. - FELLITI, M.: Diagnostic of inverter three Levels Associated with Asynchronous Machine, International Journal of Engineering Research and Technology IJERT, Vol. 2, Issue 9, September 2013.

[12] MENDAZ, K. - BOUNOUA, H. - FELLITI, M.: Comparative Study of Diagnostic of inverter three and five Levels Associated with Asynchronous Machine, International Journal of Science and Research (IJSR), Vol. 2, Issue 9, September 2013.

[13] HAMMOUMI, A. - MASSOUM, A. MEROUFEL, A. - WIRA, P.: Application de réseaux de neurons pour la machine asynchrone sans 
capteur mécanique, Acta Electrotechnica, Vol. 53, No. 2, 2012, pp. 99-104.

[14] PU SHI - ZHENG CHEN - YURIY VAGAPOV: Fault Detection and Diagnosis of Induction Machines based on Wavelet and Probabilistic Neural Network, International Journal of Computer Applications, Vol. 69, No. 14, 2013, pp. 44-50.

Received September 7, 2016, accepted February 13, 2017

\section{BIOGRAPHIES}

Kheira Mendaz was born in Ain Témouchent, Algeria, in 1976. He received the engineer in electrical engineering from Djillali Liabes University, Sidi Bel Abes, Algeria, in
2005, the M.S degrees in electrical engineering from Sidi Bel Abbes University, Algeria, in 2008, and Ph.D degrees in electrical engineering from Sidi Bel Abbes University, Algeria, in 2015. His research interests include highfrequency power conversion, magnetic design, EMI reduction techniques, power electronics and EMC in power converter.

Houria Bounoua received the B.S degree in electrical engineering from USTO (Technology Sciences University of Oran), Algeria in 1983, the M.S. and Ph.D degrees in electrical engineering from Sidi Bel Abbes University, Algeria, in 1991 and 2004, respectively. Since 1983, she is a teaching member and involves in research on Numerical command on Power Systems, at Sidi Bel Abbes University (Algeria). 